Special issue of the International Conference on Computational and Experimental Science and Engineering (ICCESEN 2014)

\title{
Principles Creation Integrated On-Line Access System for Free Standing Renewable Energy Technology (RET)
}

\author{
O. Kisseleva*, B. Akhmetov, and P. Kharitonov \\ Satpayev Kazakh National Technical University K. Satpayev, Almaty, Kazakhstan
}

\begin{abstract}
This paper presents the development of the structure of the integrated ON-LINE information system for collective use of renewable energy. Information about each installation including its location identification and capacity which is potentially available for external users is accessible via internet. Structure of each installation will include an intellectual control and registration module (ICRM) for electric energy available to external users. Where necessary any consumer can request reserve energy generated in near-by located free standing istallations for external use and make a decision to approach to any of those installation.
\end{abstract}

DOI: 10.12693/APhysPolA.128.B-258

PACS: $89.70 .+\mathrm{C}$

\section{Introduction}

At the beginning of XXI century global energy development vector has turned around towards enhanced application of free standing technology driven by renewable energy sources - solar radiation, air and water, ebb and flow, mechanical flactuations and vibrations etc.

Centralized energy supply has a number of relevant drawbacks in terms of provision of safe life activity:

- low protectability against terroristic impacts and natural disasters;

- considerable costs associated with delivery of hydrocarbon fuels and useless energy losses within electric lines;

- environmental pollution with combustion products of hydrocarbon fuels used by heat electropower plants.

\section{An option of solution of the issue}

Modern microelectronic bases along with development of IT technologies create new opportunities for building environment friendly integrated energy supply systems featuring increased viability and energy efficiency. Currently operating and newly introduced smaller wind- and hydroenergy installations as well as solar photovoltaic stations will become supporting points within these systems. The overall number of free standing energy installations of smaller and average capacity increase continuously while energy consumption rate is quite low. As a rule these are istallations for personal use which are not equipped with energy accumulators. The energy use factor can be significantly increased through application of additional systems of uninterrupted power extraction with energy accumulation in electric and heat storage

\footnotetext{
* corresponding author; e-mail: ident06@mail.ru
}

batteries [1]. These systems enable splitting energy accumulation and consumption processes of free standing installations with consideration of time factor. Besides, customer energy supply with power consumption which is much higher than rated output capacity of electric generator of the installation is possible.

For example, with rated output capacity of photovoltaic installation $P$ (output) $=100 \mathrm{~W}$ and daylight hours $T_{c}=12$ hours electrical power supply is possible (through an inventor), with energy accumulated in electric storage battery, electric load $P_{H}=1000 \mathrm{~W}$ within time period

$$
T_{n}=\eta P(\text { output }) T_{c} / P_{n},
$$

where $\eta \geq 0.85$ - invertor efficiency rate. In this case electric power supply is possible for a load with power consumption of $1000 \mathrm{~W}$ for 1 hour at any time of day.

Incomplete consumption of generated electric energy is a specific feature of installations for personal use. The above mentioned photovoltaic installation can be placed at a country house an owner of which comes there twice a week and uses generated power for an iron and a kettle. The rest 5 days of the week the energy generated is not practically used. From the viepoint of common sense the capacity $E_{a}$ of electric accumulator will be selected on condition:

$$
E_{a} \geq \eta P(\text { output }) T_{n} U_{n} / U_{a}
$$

where $U_{n}$ - rated voltage of electric load, $U_{a}$ - output voltage of electric accumulator. Is unreasonable for a customer to use electric accumulators with capacity much higher that is required for power supply of his home appliances within a known time period $T_{n}$. As a result energy use factor $(\beta)$ of a village photovoltaic installation will be equal to:

$$
\beta=2 / 7 \cdot 100 \%=28.5 \% \text {. }
$$

\section{Conclusion}

An option to significantly increase use factor of free standing electric installations will be as follows. 
Information about each installation including its location identification and capacity which is potentially available for external users is accessible via internet. Structure of each installation will include an intellectual control and registration module (ICRM) for electric energy available to external users. Where necessary any consumer can request reserve energy generated in near-by located free standing istallations for external use and make a decision to approach to any of those installation. Each free standing installation is equipped with a special electric socket for connection of external users. The socket has USB port for data entry via flash-card which will be considered when settling accounts between a customer and the owner of the installation.
Thus there is an opportunity for more complete use of energy generated through free standing electric installations and more options of power supply to the customers moving around the countryside.

\section{References}

[1] P.T. Kharitonov, Uninterrupted customer power supply system based on wind-driven generators, Patent RU No. 104253 of 10.05.2011 for PM.

[2] B.S. Akhmetov, L.Sh. Balgabayeva, O.V. Kiselyova, P.T. Kharitonov, in: Proceedings of the II- International Scientific Conference "High Tech Means Sustainable Development", Almaty 2013, Vol. II, Almaty 2013, p.57. 